\title{
Reasons for cancellation of elective operations at a major teaching referral hospital in Jordan
}

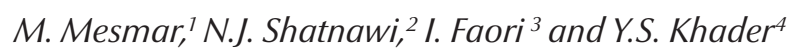

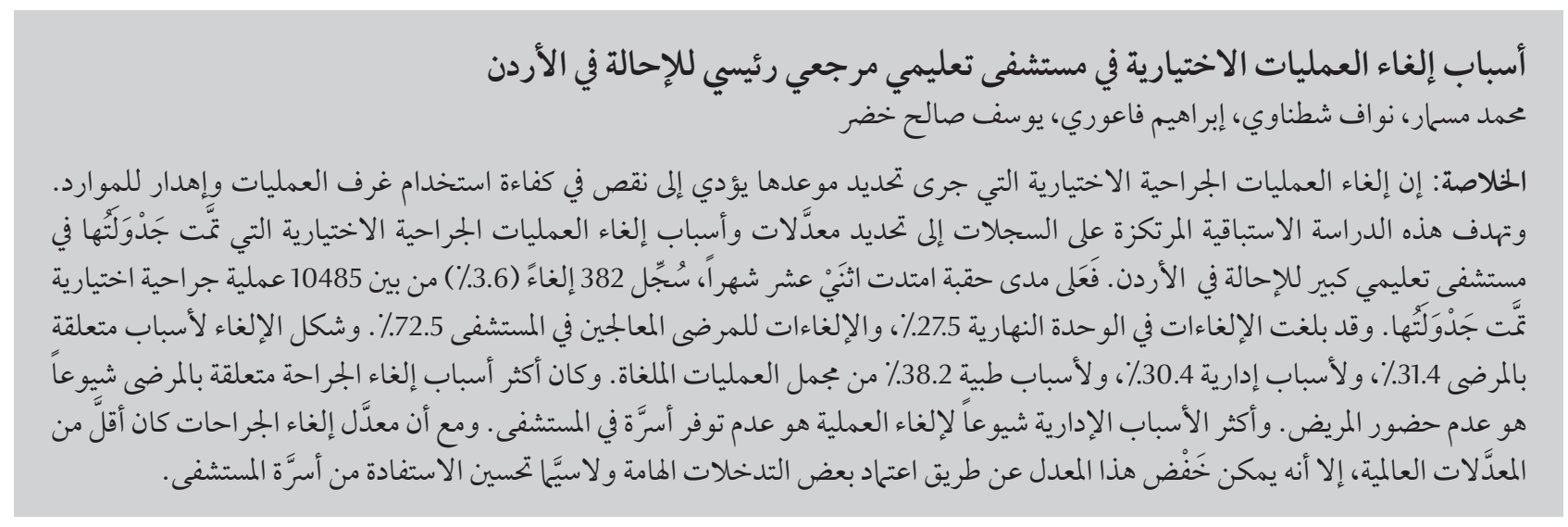

ABSTRACT Cancellation of elective scheduled operations leads to an inefficient use of operating room time and a waste of resources. This prospective records-based study aimed to determine the rate of and reasons for cancellations of scheduled elective surgical operations in a major teaching referral hospital in Jordan. Over a period of 12 months, cancellation was recorded in 382 (3.6\%) of 10485 scheduled elective surgical operations. Day unit cancellations accounted for $27.5 \%$ and inpatient cancellations for $72.5 \%$. Patient-related reasons, administrative and medical reasons accounted for $31.4 \%, 30.4 \%$ and $38.2 \%$ of all cancelled operations respectively. The most common patient-related reason for cancellation was patient non-attendance. The most common administrative reason for cancellations was unavailability of hospital admission beds. Although the cancellation rate was low in comparison with the reported rates worldwide, reductions might be achieved by adopting some important interventions, especially better bed utilization.

Motifs d'annulation des interventions chirurgicales programmées dans un grand centre hospitalier universitaire de recours en Jordanie

RÉSUMÉ L'annulation d'interventions chirurgicales programmées conduit à une utilisation inefficace des plages opératoires disponibles et au gaspillage des ressources. La présente étude prospective, fondée sur des dossiers de patients, visait à déterminer le taux d'annulation des interventions chirurgicales programmées dans un grand centre hospitalier universitaire de recours en Jordanie, et les motifs de ces annulations. Sur une période de douze mois, 382 interventions programmées sur 10485 (soit 3,6 \% d'entre elles) ont été annulées. Les annulations concernaient pour $27,5 \%$ d'entre elles des soins ambulatoires, et $72,5 \%$ d'entre elles une intervention avec hospitalisation. Les motifs liés aux patients, les raisons administratives et les causes médicales représentaient respectivement $31,4 \%, 30,4 \%$ et 38,2 \% de l'ensemble des annulations. L'absence du patient était le motif le plus fréquent des annulations liées à ces derniers. La raison administrative la plus courante était le manque de lits. Même si le taux d'annulation est faible par rapport aux autres taux dans le monde, il pourrait encore diminuer grâce à l'adoption de mesures importantes telles qu'une meilleure utilisation des lits.

${ }^{7}$ Department of Orthopaedic Surgery; ${ }^{2}$ Department of Surgery; ${ }^{3}$ Department of Nursing; ${ }^{4}$ Department of Public Health, Faculty of Medicine, King Abdullah University Hospital, Jordan University of Science and Technology, Irbid, Jordan (Correspondence to Y.S. Khader: yousef.k@excite.com). Received: 20/12/09; accepted: 28/01/10 


\section{Introduction}

Considerable resources are invested in maintaining a well-functioning operating theatre. Cancellation of elective scheduled operations leads to an inefficient use of operating room time and a waste of resources [1-3]. The disruptions which cancellations create to patients, their families and the medical teams are high. Cancellation is a major problem in most hospitals. The incidence and reasons of cancellation differ from one hospital to another, with rates varying from $10 \%$ to $40 \%[4,5]$.

In a comprehensive quality improvement programme the rate of surgical cancellation is one of the quality indicators for operative theatres. The reasons for cancellations can be patient-related, administrative or medical. For each of these reasons, different interventions can be implemented to reduce cancellations to the minimum. The commonest reasons for cancellation of elective surgical procedures reported in previous studies included lack of theatre time [6], non-availability of recovery room beds and patients failing to attend [7].

This study was conducted to determine the rate and reasons for cancellations of scheduled elective surgical operations in a major teaching referral hospital in Jordan. Identifying the avoidable reasons would help to implement interventions to improve the efficiency of operating room services.

\section{Methods}

A prospective survey was conducted in King Abdullah University hospital between August 2005 and July 2006 to identify cancelled day-case and inpatient elective operations. This is the main teaching and tertiary referral hospital in the north of Jordan with 650 beds, 20 operating theatres and a 16 bed daycare surgery unit. Operating schedules are submitted to the operative suite for each working day at 15.00 the previous day. Any additional elective operations after that time have to be approved by the senior consultant of anaesthesia. Emergency operations are booked as they appeared on the emergency board located in the theatre reception area and there is an assigned operative theatre for emergencycases.Life-savingemergency cases can be carried out by interruptions of any of the theatres according to the state of urgency.

Operative cancellations were defined as those cases that were booked in the operative list (schedule) and did not have the planned surgery on the intended date. All cancellations of scheduled elective operations of patients who did not attend for admission to the hospital or were not admitted because of bed unavailability were included. Patients who died before the time of their scheduled surgery were excluded.

Cancellations of elective scheduled operations in the period from August 2005 to July 2006 were reviewed prospectively. All cancellations were recorded in a predesigned form which included information about the age of the patient, hospital identification number, date of cancellation, type of operation, the surgeon and the anaesthetist, any associated medical problems and the presumed reasons for cancellations for inpatients and day care surgery unit. For each cancelled operation, the form was filled by the senior registered nurse in charge of the operative suite and signed by the consultant of anaesthesia in charge. The medical records of cancelled cases were reviewed in order to identify associated medical conditions, preoperative anaesthetic evaluations and recommended management plans to improve the preoperative status of patients with associated chronic medical problems. Patients who did not attend were contacted by the theatre secretary to establish the reason for non-attendance.

Cancellation reasons were classified by the authors into 3 major categories: patient-related, administrative-related and medical-related.

Frequencies and percentages were reported to describe the data. Data were analysed using SPSS, version 15.

\section{Results}

Over a period of 12 months, 10485 elective surgical operations were scheduled. A total of 10103 elective operations were performed on the planned date. Cancellation was recorded in 382 cases (3.6\%) (215 for admitted patients and 167 for non-admitted patients). Day unit cancellations accounted for $27.5 \%$ of all cancelled operations and inpatient cancellations for $72.5 \%$.

Table 1 shows the reasons for cancellation according to the location of admissions. Patient-related, administrative-related and medical-related reasons accounted for $31.4 \%, 30.4 \%$ and $38.2 \%$ of the cancelled operations respectively. The most common patient-related reason for cancellation was patient nonattendance which accounted for $23.0 \%$ of all cancellations. Patients' request for cancellation accounted for $5.8 \%$ of all cancellations. The most common administrative reason for cancellations was unavailability of hospital admission beds which accounted for $20.7 \%$ of all cancellations. Acute medical illnesses were the most common medical reasons for cancellations.

Table 2 shows the number of cancellations according to surgical specialty, nature and location of admission. Cancellations among patients admitted for ophthalmic surgery accounted for $20.9 \%$ of all cancellations, while general surgical cancellations were $21.5 \%$ of all cancelled cases.

\section{Discussion}

Surgical cancellation is defined as a scheduled surgery which is not done at the intended date. Narrow or wide 


\begin{tabular}{|c|c|c|c|c|}
\hline \multirow[t]{2}{*}{ Reason } & \multirow{2}{*}{$\begin{array}{c}\text { Inpatients } \\
\text { No. }\end{array}$} & \multirow{2}{*}{$\begin{array}{c}\text { Day unit } \\
\text { No. }\end{array}$} & \multicolumn{2}{|c|}{ Total $(n=382)$} \\
\hline & & & No. & $\%$ \\
\hline Patient-related reasons & 56 & 64 & 120 & 31.4 \\
\hline Patient failed to attend & 30 & 58 & 88 & 23.0 \\
\hline Patient request & 19 & 3 & 22 & 5.8 \\
\hline Patient not fasting & 7 & 3 & 10 & 2.6 \\
\hline Administrative-related reasons & 98 & 18 & 116 & 30.4 \\
\hline No bed available & 68 & 11 & 79 & 20.7 \\
\hline Overloaded schedule & 14 & 6 & 20 & 5.2 \\
\hline Lack of staff & 7 & 1 & 8 & 2.1 \\
\hline Lack of equipment & 6 & 0 & 6 & 1.6 \\
\hline No blood available & 3 & 0 & 3 & 0.8 \\
\hline Medical-related reasons & 122 & 24 & 146 & 38.2 \\
\hline Upper respiratory tract infection & 35 & 14 & 49 & 12.8 \\
\hline High blood pressure & 39 & 3 & 42 & 11.0 \\
\hline Unfit because of other medical conditions & 22 & 1 & 23 & 6.0 \\
\hline Acute illness & 7 & 1 & 8 & 2.1 \\
\hline Change of treatment plan & 9 & 3 & 12 & 3.1 \\
\hline Abnormal laboratory results & 7 & 0 & 7 & 1.8 \\
\hline Patient taking aspirin & 3 & 2 & 5 & 1.3 \\
\hline
\end{tabular}

definitions are adopted by different hospitals. Narrowly defined cancellations include admitted scheduled operations which are not performed on the intended date [8]. This study reported all reasons for cancellations including patient-, administrative- and medical-related reasons. The rate of cancellation in this study was $3.6 \%$. Hospitals that define cancellation narrowly have reported a rate of less than $10 \%[8,9]$, while hospitals that defined cancellations of all types have reported a rate as high as $24 \%$ [10-14].

Another source of variation in the reported rates of cancellations is the approach to data collection, whether it is prospective or retrospective [15]. In this study, data on cancellation were collected prospectively; therefore, underreporting of cancellations is expected to be minimal. The low cancellation rate at this hospital might be related to the monitoring of cancellation as a

\begin{tabular}{|c|c|c|c|c|c|c|}
\hline \multirow[t]{3}{*}{ Specialty } & \multirow{2}{*}{\multicolumn{2}{|c|}{ Total }} & \multicolumn{2}{|c|}{ Scheduled admitted patients } & \multicolumn{2}{|c|}{$\begin{array}{l}\text { Scheduled non-admitted } \\
\text { patients }\end{array}$} \\
\hline & & & Inpatients & Day unit & Inpatients & Day unit \\
\hline & No. & $\%$ & No. & No. & No. & No. \\
\hline General surgery & 82 & 21.5 & 35 & 7 & 23 & 17 \\
\hline Ophthalmology & 80 & 20.9 & 43 & 7 & 17 & 13 \\
\hline Orthopaedic surgery & 69 & 18.1 & 33 & 5 & 16 & 15 \\
\hline Urology & 62 & 16.2 & 24 & 8 & 17 & 13 \\
\hline ENT surgery & 45 & 11.8 & 18 & 6 & 13 & 8 \\
\hline Neurosurgery & 20 & 5.2 & 13 & 2 & 4 & 1 \\
\hline Gynaecology & 12 & 3.1 & 6 & 1 & 4 & 1 \\
\hline Plastic surgery & 8 & 2.1 & 4 & 0 & 3 & 1 \\
\hline Maxillofacial & 4 & 1.0 & 3 & 0 & 1 & 0 \\
\hline Total & 382 & 100.0 & 179 & 36 & 98 & 69 \\
\hline
\end{tabular}

$E N T=$ ear, nose and throat. 
quality indicator in the hospital quality improvement programme.

For a multi-dimensional problem such as surgical cancellations, it is important to address major reasons that result in cancellations. Medical-related reasons contributed to $38.2 \%$ of cancellations. Among the medical reasons, acute medical illness contributed the most, with acute upper respiratory tract infection as the most common reason. These cancellations are considered unavoidable; no one would wish to risk the patient's life for an elective surgery. However, cancellation of elective operation for acute upper respiratory tract infections is controversial. There is debate that uncomplicated cases of upper respiratory tract infection can safely be anesthetized without increasing postoperative complications [16-19].

Elevated blood pressure as a cause for cancellations contributed to $11.0 \%$ of all cancelled operations. Longstanding hypertension may be associated with perioperative cardiovascular complications [20] and perioperative cardiac death [21]. Preoperative elevated blood pressure on the other hand was not found to be associated with major perioperative cardiac complications $[20,22]$. However, patients with arterial blood pressure of $>210 / 120$ $\mathrm{mmHg}$ (stage 4) present a real risk of periopertive complication and death. The uncertainty of the highest safe blood pressure for anaesthesia results in variations in practice [23]. Perioperative blood pressure elevations might be due to the stress and fear of operations. Adequate preoperative explanation through proper channels of communication with the patients might minimize the contribution of these factors. Patients with chronic illnesses are at higher risk if they are subjected to the trauma of surgery and general anaesthesia' however, these patients require preoperative optimization of their medical status. Most patients in this study labelled as unfit for general anaesthesia had their operation performed on a later date. Furthermore, most of them were inpatient cases. This finding might indicate some degree of suboptimal preoperative hospital care for these patients.

Administrative-related reasons accounted for $30.4 \%$ of all cancellations, with unavailability of admission beds being the most common reason. All administrative reasons were basically a result of communication problems, which are avoidable Administrative reasons accounted for $45 \%$ of all cancellations in some studies $[10,12]$. Such problems can be solved by improving the management of patient beds.

In conclusion, although our cancellation rate was low in comparison with the reported rates worldwide, a major reduction in the cancellation rate could be achieved by adopting a few important interventions, such as creating a bed utilization manager position in the hospital. An aesthetic protocol defining the parameters which will render patients as unfit for elective surgery needs to be communicated to surgical specialties and consultants in medical and paediatric departments.

\section{References}

1. Robb WB et al. Are elective surgical operations cancelled due to increasing medical admissions? Irish Journal of Medical Science, 2004, 173:129-132.

2. Tait AR et al. Cancellation of pediatric outpatient surgery: economic and emotional implications for patients and their families. Journal of Clinical Anesthesia, 1997, 9:213-219.

3. Ivarsson B et al. Patient reactions to cancelled or postponed heart operations. Journal of Nursing Management, 2002, 10:75-81.

4. Rai M, Pandit JJ. Day of surgery cancellation after nurse-led preassessment in an elective surgical centre: the first 2 years. Anaesthesia, 2003, 58:692-699.

5. Schofield WN et al. Cancellation of operations on the day of intended surgery at a major Australian referred hospital. Medical Journal of Australia, 2005, 182:612-615.

6. Pandit JJ, Carey A. Estimating the duration of common elective operations: implications for operating list management. Anesthesia, 2006, 61:768-776.

7. Audit Commission. Operating theatres. Review of national findings. London, Her Majesty's Stationery Office, 2003.

8. Fischer SP. Development and effectiveness of an anesthesia preoperative evaluation clinic in a teaching hospital. Anesthesiology, 1996, 85:196-206.

9. Frost EA. Outpatient evaluation: a new role for the anesthesiologist. Anesthesia and Analgesia, 1976, 55:307-310.
10. Hand R, Levin P, Stanziola A. The causes of cancelled elective surgery. Quality Assurance and Utilization Review, 1990, 5:2-6.

11. Lacqua MJ, Evans JT. Cancelled elective surgery: an evaluation. American Surgeon, 1994, 60:809-811.

12. Livingstone $\mathrm{Jl}$ et al. Role of pre-admission clinics in a general surgical unit: a 6-month audit. Annals of the Royal College of Surgeons of England, 1993, 75:211-212.

13. Basu S et al. Impact of questionnaires and telephone screening on attendance for ambulatory surgery. Annals of the Royal College of Surgeons of England, 2001, 83:329-331.

14. Kerridge $\mathrm{R}$ et al. The perioperative system: a new approach to managing elective surgery. Anaesthesia and Intensive Care, 1995, 23:591-596.

15. Pollard JB, Olson L. Early outpatient preoperative anesthesia assessment: does it help to reduce operating room cancellations? Anesthesia and Analgesia, 1999, 89:502-505.

16. Tait AR, Knight PR. The effects of general anesthesia on upper respiratory tract infections in children. Anesthesiology, 1987, 67:930-935.

17. Levy $L$ et al. Upper respiratory tract infections and general anaesthesia in children. Peri-operative complications and oxygen saturation. Anaesthesia, 1992, 47:678-682.

18. Tait AR, Knight PR. Intraoperative respiratory complications in patients with upper respiratory tract infections. Canadian Journal of Anaesthesia, 1987, 34:300-303. 
19. Rolf N, Coté CJ. Frequency and severity of desaturation events during general anesthesia in children with and without upper respiratory infections. Journal of Clinical Anesthesia, 1992, 4:200-203.

20. Howell SJ et al. Risk factors for cardiovascular death after elective surgery under general anaesthesia. British Journal of Anaesthesia, 1998, 80:14-19.

21. Goldman L, Caldera DL. Risks of general anesthesia and elective operation in the hypertensive patient. Anesthesiology, 1979, 50:285-292.
22. Howell SJ et al. Hypertension, admission blood pressure and perioperative cardiovascular risk. Anaesthesia, 1996, 51:1000-1004.

23. Dix P, Howell S. Survey of cancellation rate of hypertensive patients undergoing anaesthesia and elective surgery. British Journal of Anaesthesia, 2001, 86:789-793.

\section{Management effectiveness initiatives}

The management of health care is a pivotal factor in the delivery of effective health service with growing recognition of the key role that non-clinical activities play in the way that health care is delivered. Management effectiveness is crucial in all health care settings: hospitals, primary health care clinics, mobile units, laboratories and pharmacies.

The WHO's Regional Office for the Eastern Mediterranean (EMRO) works in partnership with ministries of health of the Region to strengthen the way in which health care facilities and professionals are managed. The ultimate aim is to improve their functioning by working towards greater effectiveness, efficiency, quality and coverage of services, which will lead to better health outcomes.

The main aspects of EMRO's work within the field of health management involve providing technical assistance and support to countries in the Region to:

- Assess the performance of health services

- Improve the delivery of health care services through capacity-building

- Strengthen district health systems as the viable decentralized entity of the health care delivery system

- Enhance the different lines of accountability and communication between levels of care

- Improve the credibility of health services

- Develop a strategy to find the best balance of public-private mix. 